\title{
Effects of swimming and walking on aspects related to the health of police officers
}

http://dx.doi.org/10.11606/1807-5509201700020333

\author{
Franciele Cascaes da SILVA* \\ Beatriz Angélica Valdivia ARANCIBIA* \\ Elizandra Gonçalves FERREIRA* \\ Ricardo Moreno LIMA** \\ Paulo José Barbosa GUTIERRES FILHO** \\ Rudney da SILVA*
}

"Centro de Ciências da

Saúde e do Esporte, Universidade do Estado de Santa Catarina, Florianópolis, SC, Brasil.

${ }^{* *}$ Faculdade de Educação Física, Universidade de Brasília, Brasilia, DF, Brasil.

\begin{abstract}
The present study aimed to compare the effects of swimming and walking after 24 weeks of training on anthropometric indicators of obesity, physical activity, coronary risk and health-related quality of life among military police officers of the state of Santa Catarina, Brazil. The sample included 51 military police officers (male) whose ages ranged from 22 to 49 years, with a mean age of $35.53 \pm 7.63$ years, and who fulfilled the inclusion criteria of the study, which was conducted between the months of June and December 2012. The subjects were interviewed to collect demographic and occupational data as well as anthropometry, physical activity level and health. The volunteers were divided into the following three groups according to their preference: swimming experimental group $(n=24)$, walking experimental group $(n=24)$, and control group $(n=24)$. Statistical analyses were performed using descriptive analysis, oneway and two-way ANOVAs followed by Bonferroni's post hoc test, Student's $t$-test, the Kruskal-Wallis test and the Mann-Whitney $U$ test followed by Bonferroni's correction, the Wilcoxon test and Cohen's $d$ test. After 24 weeks of training, the waist circumference, conicity index, waist-to-height ratio, physical activity at work, vigorous activities and coronary risk were significantly different in the swimming group, and the percentages of fat, lean mass and fat mass were significantly different in the walking group. The swimming exercise program contributed to significant reductions in waist circumference, conicity index, the waist-to-height ratio and coronary risk and to increased levels of physical activity at work and vigorous activities. In addition, the walking exercise program contributed to significant reductions in relative body fat and fat mass and increased lean mass among military police officers.
\end{abstract}

KEYwords: Police; Motor activity; Anthropometry; Health; Quality of life.

\section{Introduction}

Police officers are exposed to physical and psychological risks that significantly affect several aspects of their health. ${ }^{1-5}$ Studies have shown that police officers are more likely to be obese and to have higher mortality rates due to cardiovascular disease compared to the general population. Police officers also have higher depression and stress levels than other professional groups; these conditions adversely affect their quality of life. ${ }^{6-13}$

Reports developed by health organizations recommend exercise for the general population ${ }^{14-17}$ based on physiological and psychological adaptations associated with better control of risk factors for cardiovascular disease, thus contributing to a healthier lifestyle and to improved quality of life. ${ }^{18-23}$ Although the benefits of regular physical activity are well documented in the literature, aspects related to the specificity of physical exercise targeted at the health of police officers need to be better investigated.

These gaps relate to specificities of the profession and the lifestyle adopted by police officers because they tend to exhibit low levels of sport 
and leisure physical activities, although they are considered more physically active than the general population. ${ }^{6,8,13,24-25}$ Therefore, strategies that enable cardiovascular disease prevention, professional technical improvement and health and quality of life enhancements in this population are relevant.
The present study aimed to compare the effects of swimming and walking after 24 weeks of training on anthropometric indicators of obesity, physical activity, coronary risk and health-related quality of life among military police officers of the state of Santa Catarina, Brazil.

\section{Methods}

The quasi-experimental study was approved by the institution's human research ethics committee (Protocol no. 174/2011/Comitê de Ética e Pesquisa em Seres Humanos - CEPSH da Universidade do Estado de Santa Catarina - UDESC).

\section{Sample}

The sample consisted of male military police officers of various ranks who were aged 18 years or more, with an age range of 22 to 49 years and a mean age of $35.53 \pm 7.63$ years, who were able to practice physical activities as certified by a medical professional and who agreed to fully participate in the interventions. Individuals who had any type of cardiorespiratory impairment or musculoskeletal injury that could prevent the intervention protocol to be performed were excluded from this study.

Non-randomized selection was used because of the strict ethical standards, which, despite being focused on target variables, required subjects from the experimental group to be available to participate in training sessions without any interference from authorities in the chain of command that is present in the military police corporation. All military police officers who were interested or available had the same opportunities to participate in the study.

The sampling plan was developed based on criteria compatible with experimental health research ${ }^{26}$; this plan established that at least 12 subjects per group were required. However, aiming to meet the adopted criteria and to account for the possibility of sample loss typical of experimental studies, the sample size was multiplied by two, totaling 72 subjects required for the study. Subject identification began with a collective presentation on the objectives and procedures to be adopted, in addition to the existing risks and ways to mitigate them, emphasizing the voluntary nature of participation regardless of the authority of the military chain of command. Subjects were selected only after informed consent form was obtained, thus respecting the existing national and international ethical guidelines. The period for participant recruitment was June 20 to June 30, 2012. The volunteers were divided into the following three groups according to their preference: a) swimming experimental group (SEG; $n=24)$, b) walking experimental group (WEG; $\mathrm{n}=24$ ) and $\mathrm{c}$ ) control group (CG; $\mathrm{n}=24)$.

After allocation to the three groups, the subjects were individually scheduled for evaluations that would be performed at the Santa Catarina State University and Center for Health Sciences and Sports.

\section{Analyzed Variables}

Subjects were interviewed to collect demographic and occupational data (age, rank, activities, work shift and years of service) and anthropometric indices (weight, height, waist circumference, relative body fat, lean mass and fat mass). The anthropometric assessment adopted the protocol of LOHMAN, Roche and MARTORELL ${ }^{27}$, and the variables allowed the conicity index (CI) and the waist-to-height ratio (WHtR) to be calculated.

The subjects also completed the following three questionnaires: a) the International Physical Activity Questionnaire long version (IPAQ) ${ }^{28-29}$, b) the Short Form Health Survey (SF-36) ${ }^{30-31}$ and c) the Coronary Risk Inventory, created by the Michigan Heart Association ${ }^{32}$.

\section{Physical Exercise Protocol}

Swimming (SEG) was performed in a 25 -meter semi-Olympic swimming pool with a constant temperature of $26^{\circ} \mathrm{C}$; the protocol for walking (WEG) was performed on a 5,700-meter course. Everyday occupational, recreational and sport-related activities were not limited, but volunteers were requested not to alter their usual routines. All of the above assessments were performed before (week zero) and after (week 24) the training period. 
The SEG and WEG activity programs were prepared as recommended by the American College of Sports Medicine. ${ }^{33}$ The programs included three 60-minute sessions per week for 24 weeks. The CG did not participate in any type of intervention, but evaluations were performed at weeks zero and 24 .

The exercise intensity prescription was based on the Heart Rate Reserve (HRreserve). ${ }^{33}$ The TanaKa equation ${ }^{34}$ was used to determine the maximum heart rate (HRmax). The exercise intensity in each training session was monitored individually and continuously using digital heart rate (HR) monitors (Polar ${ }^{\ominus}$ FT1) and the Borg scale of perceived exertion, which ranges from zero (none) to 10 (maximum) points. ${ }^{35}$

All exercise sessions were standardized and divided into five parts: 1) initial assessment - before exercise, with blood pressure (BP) and HR assessments; 2) preparation - composed predominantly of warm-up and stretching exercises; 3) training swimming (SEG) or walking (WEG) activities; 4) cool down or return to rest - low-intensity aerobic activities, relaxation or muscle stretching activities and 5) final evaluation - after exercise sessions, with $\mathrm{BP}$ and HR assessments.

In the SEG, the exercises performed during the first two weeks (adaptation) were conducted at intensities between 40 and $50 \%$ of the HRreserve and consisted of breathing, floating, swimming, immersion and displacement technical skills without previous guidance. During weeks three and seven (development/stabilization phase), activities to develop the front crawl, breaststroke and backstroke swimming techniques were performed at intensities between 60 and $80 \%$ of the HRreserve. During the third phase (stabilization), weeks 13-24, the intensity was maintained between 75 and $85 \%$ of the HR reserve, and in addition to individualized development, the improvement of aquatic skills and the promotion of muscle resistance and swimming speed were prioritized.

In the WEG, the exercises developed during the first phase (adaptation) included low-intensity walking with BP, HR and perceived exertion control rate monitored for two weeks. The intensity during this phase ranged from 40 to $50 \%$ of the HRreserve. Subsequently, the development/stabilization phase consisted of moderate-intensity walking (60 to $80 \%$ of the HRreserve) between weeks three and seven. During the third phase (stabilization), weeks 1324, the intensity was maintained between 75 and $85 \%$ of the HRreserve with BP, HR and perceived exertion control rate monitored.

\section{Statistical Analysis}

The statistical analysis was performed using Statistical Package for the Social Sciences (SPSS) version 20.0.

According to the recommendations of BLAND and ALtmaN ${ }^{36}$, quantitative data were treated using parametric statistics, and discrete data were treated using non-parametric statistics.

For the descriptive analysis, means, standard deviations, medians absolute and relative frequencies were used.

The anthropometric indicators of obesity were analyzed by one-way analysis of variance (ANOVA) followed by Bonferroni's post hoc test before and after interventions and by two-way ANOVA followed by Bonferroni's post hoc test. Student's $t$-test for paired samples was used to compare the participants in each exercise program. Effect measures were calculated using Cohen's d test (d) adopting the following classification: small $(\mathrm{d}=$ $0.2)$, medium $(d=0.5)$ and large $(d=0.8)$ for quantitative data. The $r$ test was used for categorical data with the formula $r=\mathrm{z} / \sqrt{\mathrm{N}}$, where $r$ is the effect size, $\mathrm{z}$ is the value of the statistic, and $\mathrm{N}$ is the sample size.

Because quality of life, coronary risk and physical activity level are non-parametric, the intergroup comparison was tested using the Kruskal-Wallis test and the Mann-Whitney $U$ test followed by Bonferroni's correction. The Wilcoxon test was applied for comparisons among the participants. The significance level used in the analyses was set at $\mathrm{p} \leq 0.05$.

\section{Results}

During the study, the 24 subjects were allocated to each of the three groups as follows: 14 subjects in the SEG, 16 subjects in the WEG and
21 subjects in the CG. Thus, during the proposed period, 51 individuals participated in the study $(\mathrm{n}=51)$. 
Silva FC, et al.

The 51 police officers who participated in the study had ages ranging from 22 to 49 years, with a mean age of $35.53 \pm 7.63$ years, and worked an average of approximately $4 \pm 0.97$ days and 698.82 \pm 336.39 minutes daily. TABLE 1 shows the characteristics of the subjects relative to rank and function as well as years of service and classification of physical activity level and coronary risk, analyzed by group.

TABLE 1 - Characteristics of the subjects relative to rank and function as well as years of service and classification of the physical activity level and coronary risk, analyzed by group.

SEG, swimming experimental group; WEG, walking experimental group; CG, control group; $n$, absolute frequency; $\%$, relative frequency.

Source: Produced by the author.

\begin{tabular}{|c|c|c|c|c|c|c|}
\hline \multirow[t]{2}{*}{ Variable } & \multicolumn{2}{|c|}{$\begin{array}{c}\text { SEG } \\
(\mathbf{n}=14)\end{array}$} & \multicolumn{2}{|c|}{$\begin{array}{c}\text { WEG } \\
(n=16)\end{array}$} & \multicolumn{2}{|c|}{$\begin{array}{c}\text { CG } \\
(n=21)\end{array}$} \\
\hline & $\mathbf{n}$ & $\%$ & $\mathbf{n}$ & $\%$ & $\mathbf{n}$ & $\%$ \\
\hline \multicolumn{7}{|l|}{ Rank } \\
\hline Soldier & 8 & 57.1 & 10 & 62.5 & 13 & 61.9 \\
\hline Corporal & 1 & 7.1 & 1 & 6.3 & 6 & 28.6 \\
\hline Sergeant & 1 & 7.1 & 5 & 31.3 & 2 & 9.5 \\
\hline Lieutenant & 3 & 21.4 & 0 & 0 & 0 & 0 \\
\hline Major & 1 & 7.1 & 0 & 0 & 0 & 0 \\
\hline \multicolumn{7}{|l|}{ Function } \\
\hline Predominantly administrative & 6 & 42.9 & 4 & 25 & 4 & 19 \\
\hline Predominantly operational & 8 & 57.1 & 12 & 75 & 17 & 81 \\
\hline \multicolumn{7}{|l|}{ Years of service } \\
\hline $1-10$ years & 6 & 42.9 & 5 & 31.3 & 10 & 47.6 \\
\hline $11-20$ years & 5 & 35.7 & 4 & 25 & 5 & 23.8 \\
\hline $21-30$ years & 3 & 21.4 & 7 & 43.8 & 6 & 28.6 \\
\hline \multicolumn{7}{|c|}{ Physical activity level classification } \\
\hline Insufficiently active & 1 & 7.1 & 0 & 0 & 4 & 19.0 \\
\hline Little active & 4 & 28.6 & 6 & 37.5 & 7 & 33.3 \\
\hline Active & 4 & 28.6 & 3 & 18.8 & 2 & 9.5 \\
\hline Very active & 5 & 35.7 & 7 & 43.8 & 8 & 38.1 \\
\hline \multicolumn{7}{|l|}{ Coronary risk classification } \\
\hline Well below average risk & 1 & 7.1 & 0 & 0 & 1 & 4.8 \\
\hline Below average risk & 5 & 35.7 & 5 & 31.3 & 8 & 38.1 \\
\hline Medium risk & 8 & 57.1 & 8 & 50 & 9 & 42.9 \\
\hline Moderate risk & 0 & 0 & 3 & 18.8 & 3 & 14.3 \\
\hline
\end{tabular}

The analyses conducted before the experimental period did not indicate significant differences between the groups for any of the variables, i.e., the subjects were in the same conditions regarding age of the subject, years of service, minutes of work per day, days of work per week, and classification of physical activity level and coronary risk.

The comparison of anthropometric indicators of obesity after the interventions showed significant differences in the means between groups for relative body fat $(\mathrm{F}(1.50)=4.69, \mathrm{p}=0.014)$, and the differences found between the walking and swimming groups $(\mathrm{p}=0.014)$ were in favor of the WEG. Significant differences were also observed for relative body fat before and after the interventions (TABLE 2).

The intragroup comparisons showed significant differences in the means of the of waist circumference $(\mathrm{t}(50)=4.33, \mathrm{p}=0.001)$, CI $(\mathrm{t}(50)=3.28$, $\mathrm{p}=0.006)$ and WHtR $(\mathrm{t}(50)=3.68, \mathrm{p}=0.003)$ in the SEG and in the means of the fat percentage $(\mathrm{t}(50)=2.45, \mathrm{p}=0.027)$, lean mass $(\mathrm{t}(50)=-2.96$, $\mathrm{p}=0.01)$ and fat mass $(\mathrm{t}(50)=2.06, \mathrm{p}=0.05)$ in the WEG (TABLE 2). 
TABLE 2 - Comparison between the means of anthropometric indicators of obesity in the pre- and postexperimental periods, main effects (time) and interaction (group $\mathrm{X}$ time).

\begin{tabular}{|c|c|c|c|c|c|c|c|c|c|c|}
\hline \multirow{3}{*}{ Variable } & \multicolumn{6}{|c|}{ Changes from baseline to 24 weeks } & \multicolumn{4}{|c|}{ Two-way ANOVA } \\
\hline & \multicolumn{2}{|c|}{ SEG } & \multicolumn{2}{|c|}{ WEG } & \multicolumn{2}{|c|}{ CG } & \multirow{2}{*}{$\begin{array}{c}\text { Main effect } \\
\text { (time) }\end{array}$} & \multirow{2}{*}{$\begin{array}{c}\mathrm{p} \\
\text { value }\end{array}$} & \multirow{2}{*}{$\begin{array}{l}\text { Interaction } \\
\text { (group } \mathrm{x} \\
\text { time) }\end{array}$} & \multirow{2}{*}{$\begin{array}{c}\mathrm{p} \\
\text { value }\end{array}$} \\
\hline & Pre & Post & Pre & Post & Pre & Post & & & & \\
\hline WCIR (cm) & $87.96 \pm 10.17$ & $84.98 \pm 9.49^{2}$ & $92.31 \pm 11.43$ & $91.76 \pm 13.21$ & $87.40 \pm 9.61$ & $87.85 \pm 11.79$ & $F_{(1,101)}=0.21$ & 0.646 & $\mathrm{~F}_{(1,101)}=0.20$ & 0.814 \\
\hline CI $(\mathbf{c m})$ & $1.18 \pm 0.07$ & $1.14 \pm 0.06^{a}$ & $1.20 \pm 0.07$ & $1.18 \pm 0.08$ & $1.18 \pm 0.04$ & $1.16 \pm 0.07$ & $\mathrm{~F}_{(1,101)}=2.30$ & 0.133 & $F_{(1,101)}=0.23$ & 0.78 \\
\hline WHtR (cm) & $0.50 \pm 0.05$ & $0.48 \pm 0.05^{\mathrm{a}}$ & $0.53 \pm 0.06$ & $0.52 \pm 0.07$ & $0.50 \pm 0.05$ & $0.49 \pm 0.06$ & $\mathrm{~F}_{(1,101)}=0.39$ & 0.533 & $F_{(1,101)}=0.06$ & 0.940 \\
\hline RBF (\%) & $23.33 \pm 7.79$ & $20.51 \pm 6.95$ & $32.09 \pm 8.22$ & $27.84 \pm 6.12^{a}$ & $28.05 \pm 8.49$ & $25.92 \pm 7.07$ & $F_{(1,101)}=4.12$ & $0.045^{\mathrm{b}}$ & $\mathrm{F}_{(1,101)}=0.18$ & 0.832 \\
\hline LM (kg) & $62.70 \pm 11.40$ & $63.99 \pm 8.17$ & $57.95 \pm 8.48$ & $62.43 \pm 9.10^{2}$ & $59.01 \pm 8.94$ & $61.20 \pm 8.79$ & $\mathrm{~F}_{(1,101)}=2.08$ & 0.152 & $\mathrm{~F}_{(1,101)}=0.25$ & 0.779 \\
\hline FM (kg) & $18.97 \pm 6.89$ & $18.90 \pm 6.30$ & $27.43 \pm 10.69$ & $23.78 \pm 7.52^{\mathrm{a}}$ & $23.78 \pm 10.90$ & $22.23 \pm 10.97$ & $F_{(1,101)}=0.64$ & 0.425 & $\mathrm{~F}_{(1,101)}=0.38$ & 0.682 \\
\hline
\end{tabular}

The absolute delta and percentage delta variation, which is the variation between the two assessments, revealed that waist circumference, CI, WHtR, relative body fat and fat mass decreased and lean mass increased after the swimming and walking exercises. The $d$ 'statistics showed that the

magnitudes of the effects ranged from 0.26 to 0.52 for measures relative to swimming and from 0.39 to 0.59 for measures relative to walking, which according to Cohen's convention, suggests small and medium effects, respectively, on these variables (TABLE 3).

TABLE 3 - Absolute delta $(\Delta)$, percentage delta $(\Delta \%)$ and effect magnitude $\left(d^{\prime}\right)$.

\begin{tabular}{lcccccccccc}
\hline \multirow{2}{*}{ Variables } & \multicolumn{3}{c}{ SEG } & \multicolumn{3}{c}{ WEG } & \multicolumn{3}{c}{ CG } \\
\cline { 2 - 10 } & $\boldsymbol{\Delta}$ (delta) & $\boldsymbol{\Delta} \%$ & $\boldsymbol{d}^{\prime}$ & $\boldsymbol{\Delta}$ (delta) & $\boldsymbol{\Delta} \%$ & $\boldsymbol{d}^{\prime}$ & $\boldsymbol{\Delta}$ (delta) & $\boldsymbol{\Delta}^{\prime} \%$ & $\boldsymbol{d}^{\prime}$ \\
\hline WCirc (cm) & 2.97 & 3.39 & 0.30 & 0.54 & 0.60 & - & 0.44 & 0.51 & - \\
CI (cm) & 0.04 & 3.39 & 0.52 & 0.02 & 1.67 & - & 0.02 & 1.69 & - \\
WHtR cm) & 0.02 & 4.00 & 0.26 & 0.01 & 1.89 & - & 0.01 & 2.00 & - \\
RBF (\%) & 2.82 & 12.09 & - & 4.25 & 13.24 & 0.59 & 2.13 & 7.59 & - \\
LM (kg) & -1.29 & -2.06 & - & -4.48 & -7.73 & 0.50 & -2.19 & -3.71 & - \\
FM (kg) & 0.07 & 0.37 & - & 3.65 & 13.31 & 0.39 & 1.55 & 6.52 & - \\
\hline
\end{tabular}

The comparison of the health-related quality of life components and physical activity domains between groups after the interventions revealed significant differences for the mind component $(\mathrm{K}=6.70, \mathrm{p}=0.035)$. The SEG and CG differed from each other $(U=72.5, p=0.011)$, in favor of the SEG.

No significant differences in the health-related quality of life components were found between participants in the experimental groups. Regarding physical activity domains, significant differences were found between participants from the SEG for metabolic equivalents (METs) at work $(Z=-2.073$, $\mathrm{p}=0.038)$ and for vigorous activities $(\mathrm{Z}=-2.143$, $\mathrm{p}=0.032)$. A significant difference was also noted in the overall coronary risk score $(\mathrm{Z}=-1.97, \mathrm{p}=$ 0.049) in the SEG (TABLE 4).

TABLE 5 shows the absolute delta and percentage delta variation. The results indicate that most domains related to physical activity increased and the overall coronary risk score decreased after swimming and walking activities. The $r$ statistics revealed that the effect magnitudes ranged from 0.52 to 0.57 in measures associated with swimming, suggesting large effects on these variables (TABLE 5).
The values are the mean \pm SD; SEG, swimming experimental group; WEG, walking experimental group; $\mathrm{CG}$, control group; WCirc, waist circumference; $\mathrm{Cl}$, conicity index; WHtR, waist-toheight ratio; $R B F$, relative body fat; LM, lean mass; FM, fat mass. a Significant differences $(p \leq 0.05)$ intragroup - Student's t-test for paired samples b Significant differences $(p \leq 0.05)$ before versus after interventions - twoway ANOVA

Source: Produced by the author.

SEG, swimming experimental group; WEG, walking experimental group; CG, control group; WCirc, waist circumference; $\mathrm{Cl}$, conicity index; WHtR, waist-toheight ratio; RBF, relative body mass; LM, lean mass; FM, fat mass; $\Delta$, absolute delta; $\Delta \%$, percentage delta; $d$ ', statistic estimated from Cohen's equation $\left[\left(\mathrm{x}_{1}-\mathrm{x}_{2}\right) / \sigma_{\mathrm{x}}\right]$. Source: Produced by the author. 
TABLE 4 - Comparisons between the medians of physical activity domains and the overall coronary risk score in pre- and post-experimental periods.

The values are the medians; PA, physical activity; SEG, swimming experimental group; WEG, walking experimental group; CG, control group.

* Significant intragroup difference $(p \leq 0.05)$ Wilcoxon test

Source: Produced by the author.

\begin{tabular}{lcccccc}
\hline \multirow{2}{*}{ Variable } & \multicolumn{2}{c}{ SEG } & \multicolumn{2}{c}{ WEG } & \multicolumn{2}{c}{ CG } \\
\cline { 2 - 7 } & Pre & Post & Pre & Post & Pre & Post \\
\hline PA domains (METs) & & & & & & \\
\hline Work & 0 & $449.5^{*}$ & 0 & 115.5 & 0 & 0 \\
Transportation & 49.5 & 156 & 165 & 1440 & 16.5 & 16.5 \\
Household chores & 440 & 420 & 880 & 865.5 & 720 & 960 \\
Leisure & 608.5 & 1099 & 699 & 594 & 240 & 528 \\
Mild activities & 445.5 & 462 & 371.25 & 2240 & 198 & 379.5 \\
Moderate activities & 1160 & 1600 & 1460 & 1440 & 720 & 1240 \\
Vigorous activities & 480 & $1080^{*}$ & 480 & 1440 & 0 & 480 \\
\hline Coronary risk & 18.5 & $16^{*}$ & 21.5 & & & \\
\hline Overall score & \multicolumn{7}{c}{} & & & & \\
\hline
\end{tabular}

TABLE 5 - Absolute delta $(\Delta)$, percentage delta $(\Delta \%)$ and effect magnitude $(r)$ values.

SEG, swimming experimental group; WEG, walking experimental group; CG, control group.

Source: Produced by the author.

\begin{tabular}{lccccccccc}
\hline \multirow{2}{*}{ Variables } & \multicolumn{3}{c}{ SEG } & \multicolumn{3}{c}{ WEG } & \multicolumn{3}{c}{ CG } \\
\cline { 2 - 10 } & $\boldsymbol{\Delta}$ (delta) & $\boldsymbol{\Delta} \%$ & $\boldsymbol{r}$ & $\boldsymbol{\Delta}$ (delta) & $\boldsymbol{\Delta} \%$ & $\boldsymbol{\Delta}$ & $\boldsymbol{\Delta}$ (delta) & $\boldsymbol{\Delta} \%$ & $\boldsymbol{r}$ \\
\hline PA domains (METs) & & & & & & & & & \\
\hline Work & 449.5 & 44.95 & -0.55 & 115.5 & 11.55 & - & - & - & - \\
Transportation & 106.5 & 215.15 & - & 1275 & 772.73 & - & - & - & - \\
Household chores & -20 & -4.55 & - & -14.50 & -1.65 & - & 240 & 33.33 & - \\
Leisure & 490.5 & 80.61 & - & -105 & -15.02 & - & 288 & 120 & - \\
Mild activities & 17.5 & 3.93 & - & 1868.75 & 503.37 & - & 181.5 & 91.67 & - \\
Moderate activities & 440 & 37.93 & - & -20 & -1.37 & - & 520 & 72.22 & - \\
Vigorous activities & 600 & 125 & -0.57 & 960 & 200 & - & 480 & 48 & - \\
\hline Coronary risk & & & & & & & & & \\
\hline Overall score & -2.50 & -13.51 & -0.52 & -3.50 & -16.28 & - & - & - & - \\
\hline
\end{tabular}

\section{Discussion}

The main results of this study provide evidence that an exercise program of swimming or walking with moderate intensity three times per week reduced anthropometric indicators of obesity and coronary risk. In addition, the levels of physical activity at work and during vigorous activities of military police officers increased.

Of the 72 police officers interested in participating in the study, only 51 participated until the end of the program. The main reasons for dropout reported by the subjects were work shift and double shift schedules. The police officers in this study worked approximately four days per week and 12 hours per day. In addition, an individual's rank and function may interfere with adherence to exercise programs; due to the occupational requirements of a police officer, these professionals are more willing to engage in physical exercises to better perform their duties. ${ }^{13,25}$ In this study, $60.8 \%$ of the officers were soldiers who had predominantly operational functions. This type of professional work demands a high level of physical condition due to the demands of the primary function of ostensible policing. Adequate physical condition can contribute to not only individual health protection of the police involved but also public health. This contribution may occur because most effective actions against crimes can affect the quality of public security and, consequently, the care of the community. 
The low number of military police officers in the city of Florianópolis may also interfere with regular physical exercise practice. Data from the State Department of Public Safety indicate that the state of Santa Catarina has 11,400 military police officers; the city of Florianópolis has one military police officer for every 1,000 inhabitants, whereas the United Nations (UN) recommends one officer for every 250 inhabitants ${ }^{37}$, a shortfall that results in exhausting workloads. Some studies involving police officers showed that a supervised exercise program could increase the adherence of these professionals to exercise $\mathrm{e}^{13,25,38-39}$, which is corroborated by the results of this study. This increase may occur because supervised programs permit physical training control and maximize their results, which can increase motivation for physical exercise practice. Furthermore, offering these programs makes the most efficient use of the officers' free time, which is not abundant among military police due to being overworked and having long work hours and varying work schedules.

Another important factor that must be considered is the mean risk of developing coronary heart disease in most police officers the present study. According to Ramey, Downing and Franke ${ }^{40}$, police officers have a 1.7-fold greater risk of developing cardiovascular disease compared to the general population. In the study by Franke, Ramey and SHELLEY $^{8}$, predictors for cardiovascular disease in police officers included years of service as well as perceived stress and hypertension. In the study by Silva et al. $^{41}$, the CI and relative body fat as well as years of service, minutes of work per day and level of physical activity during leisure time were identified as risk factors for coronary risk in 165 military police officers studied. Similarly, the daily rhythm of work and responsibility to society can result in stressful situations, which, combined with a poor diet and physical inactivity, may promote the development of metabolic complications and cardiovascular disease. ${ }^{42}$ Regarding the physical activity level, although most subjects were classified as very physically active, when the categories of insufficiently active and slightly physically active were added, 22 subjects were included in these classifications, which could also explain the medium risk of cardiovascular disease development.

Additionally, the medium risk of developing cardiovascular disease for police officers in the present study may be because 20 police officers had waist circumferences greater than $90 \mathrm{~cm}$, as the accumulation of adipose tissue in the abdominal region greatly increases the risk for developing insulin resistance, dyslipidemia and hypertension. ${ }^{43}$ A meta-analysis conducted by Koning et al..$^{43}$ found that an increase of $1 \mathrm{~cm}$ in waist circumference may increase the risk for cardiovascular disease by $2 \%$. In a cohort study by SORENSEN et al. ${ }^{25}$, conducted among Finnish police officers, 64\% had waist circumferences greater than $94 \mathrm{~cm}$ and $38 \%$ had waist circumferences greater than $102 \mathrm{~cm}$. When combined, these data suggest that this simple and inexpensive assessment should be considered for this population because the literature reports high values of this indicator in association with cardiometabolic complications.

Despite the cardiovascular disease risk, most police officers exhibited an active physical activity level, which corroborates data from the study conducted by Minayo, Assis and Oliveira ${ }^{44}$, in which $13.1 \%$ of military police officers interviewed reported exercising four or more times per week and 38.3\% reported exercising at least once a week.

In this study, significant differences in waist circumference, CI, WHtR, physical activity level at work, vigorous activities and coronary risk were observed after a swimming exercise program. During swimming, several muscle groups are used; therefore, energy consumption and oxygen uptake are increased because of the mechanical conditions of breathing, which may be related to decreased indicators of abdominal adiposity, thus favoring coronary risk reduction and improved performance during the practice of occupational and vigorous activities. Physical exercise practice is currently encouraged as a prophylactic and therapeutic measure for all risk factors for coronary artery disease ${ }^{45}$ because weight reduction as a result of exercising contributes to lower cardiovascular morbidity and mortality. ${ }^{46-48}$

Significant differences in the percentages of fat, lean mass and fat mass were found in the WEG. The $16.4 \%$ variation in relative body fat was due to the type of exercise performed. Similar observations were made by SAVAGE et al. ${ }^{49}$. When applying a physical training program that involved 60 to 90 -min walks for four months, five to seven times per week, with 50 to $60 \% \mathrm{VO}_{2} \max$ (maximal oxygen consumption) in overweight coronary disease patients, these authors measured an effective reduction in relative body fat $(-2.9 \%)$. Therefore, walking can be an alternative to physical exercise practice, as it has low economic cost and has a high applicability level. However, although 
walking may be an interesting alternative activity, it should not be considered the only alternative because the demands of policing action require intense physical training.

The present study had some limitations. The IPAQ instrument, which is used to assess physical activity level, has memory and recollection as bias factors. For some variables, information was obtained only by participant reports, which may have caused a small degree of information bias. The exercise program was conducted only among a battalion of the Military Police of Santa Catarina, and two moderate-intensity aerobic modalities were used. In addition, the straps from the heart rate monitors are not coded to reduce interference between heart rate monitors.

Despite these limitations, this study provided important information on the effects of exercise programs for police officers. In this study, all exercise sessions were supervised, ensuring that subjects actually performed the prescribed exercises. Thus, we can conclude that a swimming exercise program contributed to significant reductions in waist circumference, CI, WHtR and coronary risk and to increased levels of physical activity at work and vigorous activities. In addition, a walking exercise program contributed to significant reductions in relative body fat and fat mass and increased lean mass among military police officers.

\section{Competing Interests}

The authors declare that no competing interests exist.

\section{Acknowledgements}

We would like to acknowledge the Military Police of Santa Catarina, the Coordination of Improvement of Higher Education Personnel - CAPES and the Foundation for Research and Innovation in the State of Santa Catarina (FAPESC).

\section{Resumo}

Efeitos da natação e caminhada nos aspectos relacionados à saúde de policiais

0 presente estudo teve como objetivo comparar os efeitos da natação e caminhada após 24 semanas de treinamento sobre os indicadores antropométricos de obesidade, atividade física, risco coronariano e com qualidade de vida relacionada á saúde entre os policiais militares do estado de Santa Catarina, Brasil. A amostra incluiu 51 policiais militares (sexo masculino) que tinham média de idade de 35,53 \pm 7,63 anos, com amplitude de 22 a 49 anos, e que preencheram os critérios de inclusão do estudo realizado entre os meses de junho-dezembro de 2012. Os sujeitos foram entrevistados e coletados os dados demográficos e ocupacionais, antropometria, nível de atividade física e saúde. Os voluntários foram divididos em três grupos de acordo com a sua preferência: Grupo Experimental de Natação $(n=24)$; Grupo Experimental de Caminhada $(n=24)$; e Grupo Controle $(n=24)$. As análises estatísticas foram realizadas utilizando análise descritiva e Anova One-Way e Anova Two-Way seguido pelo post hoc de Bonferroni, teste t de Student, teste de Kruskal-Wallis e o teste U de Mann-Whitney seguido pela correção de Bonferroni, o teste de Wilcoxon, e teste $d$ de Cohen. Houve uma diferença significativa na perimetria da cintura, indice de conicidade e relação cintura-estatura, atividade física no trabalho, atividades vigorosas e risco coronariano no grupo natação e no grupo de caminhada, houve uma diferença significativa no percentual de gordura, massa magra e massa gorda após 24 semanas de treinamento. 0 programa de natação contribuiu para reduções significativas na circunferência da perimetria da cintura, índice de conicidade e relação cintura-estatura e risco coronariano e no aumento dos níveis de atividade física no trabalho 
e atividades vigorosas. Além disso, um programa de caminhada contribuiu para reduções significativas na gordura corporal relativa e massa gorda e no aumento da massa magra entre os policiais militares.

Palavras-CHAVE: Polícia; Atividade motora; Antropometria; Saúde; Qualidade de vida.

\section{References}

1. Berg Am, Hem E, Lau B, et al. Stress in the Norwegian police service. Occup Med (Lond) 2005;55(2):113-20.

2. Chen HC, Chou FH, Chen MC, et al. A survey of quality of life and depression for police officers in Kaohsiung, Taiwan. Qual Life Res 2006;15(5):925-32.

3. Gershon RR, Lin S, Li X. Work stress in aging police officers. J Occup Environ Med 2002;44(2):160-7.

4. Greller MM, Parsons CK, Mitchell DRD. Additive effects and beyond: Occupational stressors and social buffers in a police organization. Am Psychol 1992;1:33-47. Doi: 10.1037/10116-003.

5. Violanti JM, Aron F. Sources of police stressors, job attitudes, and psychological distress. Psychol Rep 1992;72:899-904.

6. Alasagheirin MH, Clark MK, Ramey SL, et al. Body mass index misclassification of obesity among community police officers. AAOHN J 2011;59(11):469-75. Doi: 10.3928/08910162-20111017-01.

7. Andrade ER, Sousa ER, Minayo MCS. Intervenção visando a auto-estima e qualidade de vida dos policiais do Rio de Janeiro. Ciênc Saúde Coletiva 2009;14(1). Doi: 10.1590/S1413-81232009000100034.

8. Franke WD, Ramey SL, Shelley MC. Relationship between cardiovascular disease morbidity, risk factors, and stress in a law enforcement cohort. J Occup Environ Med 2002;44(12):1182-1189.

9. Lipp MEN. Stress and quality of life of senior brazilian police officers. Span J Phychol 2009;12(2):593-603.

10. Morales-Manrique CC, Valderrama-Zurián JC. Calidad de vida en policías: avances y propuestas. Pap Psicol 2012;33(1):60-67.

11. Kutlu R, Çivi S, Karaoglu O. The assessment of quality of life and depression among police officers. J Med Sci 2009;29(1).

12. Souza ER, Minayo MCS, Silva JG, et al. Fatores associados ao sofrimento psíquico de policiais militares da cidade do Rio de Janeiro. Cad Saúde Pública 2012;28(7):1297-1311. Doi: 10.1590/S0102-311X2012000700008.

13. Stamford BA, Weltman A, Moffatt RJ, et al. Status of police officers with regard to selected cardio-respiratory and body compositional fitness variables. Med Sci Sports 1978;10(4):294-7.

14. Conley MS, Rozenek R. National Strength and Conditioning Association position statement: health aspects of resistance exercise and training. Strength Cond J 2001;23(6):9-23.

15. Haskell WL, Lee IM, Pate RR, et al. Physical activity and public health: updated recommendation for adults from the American College of Sports Medicine and the American Heart Association. Med Sc Sports and Exerc 2007;39(8):1423-1434.

16. Jakicic JM, Clark K, Coleman E, et al. American College of Sports Medicine position stand. Appropriate intervention strategies for weight loss and prevention of weight regain for adults. Med Sci Sports Exerc 2001;33(12):2145-2156.

17. Pollock ML, Franklin BA, Balady GJ, et al. AHA Science Advisory. Resistance exercise in individuals with and without cardiovascular disease: benefits, rationale, safety, and prescription: an advisory from the Committee on Exercise, Rehabilitation, and Prevention, Council on Clinical Cardiology, American Heart Association; position paper endorsed by the American College of Sports Medicine. Circulation 2000;101:828-833. Doi: 10.1161/01.CIR.101.7.828.

18. Balboa-Castillo T, León-Muñoz LM, Graciani A, et al. Longitudinal association of physical activity and sedentary behavior during leisure time with health-related quality of life in community-dwelling older adults. Health Qual Life Outcomes 2011;9(1):47. Doi: 10.1186/1477-7525-9-47.

19. Herring MP, Jacob ML, Suveq C, et al. Feasibility of exercise training for the short-term treatment of generalized anxiety disorder: a randomized controlled trial. Psychother Psychosom 2012;81(1):21-8. Doi: 10.1159/000327898.

20. Hovland A, Nordhus IH, Sjobo T, et al. Comparing Physical Exercise in Groups to Group Cognitive Behaviour Therapy for the Treatment of Panic Disorder in a Randomized Controlled Trial. Behav Cogn Psychother 2012;41(4):408-32. Doi: 10.1017/S1352465812000446.

21. Viana MS, Andrade A, Back AR, et al. Nível de atividade física, estresse e saúde em bancários. Motricidade 2010;6(1):19-32.

22. Wisloff U, Stoylen A, Loennechen JP, et al. Superior cardiovascular effect of aerobic interval training versus moderate continuous training in heart failure patients: a randomized study. Circulation 2007;115(24):3086-94. 
23. Zschucke E, Gaudlitz K, Ströhle A. Exercise and physical activity in mental disorders: clinical and experimental evidence. J Prev Med Public Health. 2013;46(Suppl 1):S12-S21.

24. Silva R, Schlichting AM, Schlichting JP, et al. Aspectos relacionados à qualidade de vida e atividade física de policiais militares de Santa Catarina - Brasil. Motricidade 2012;8(3):81-89. Doi: 10.6063/motricidade.8(3).1159.

25. Sorensen L, Smolander J, Louhevaara V, et al. Physical activity, fitness and body composition of Finnish police officers: a 15-year follow-up study. Occup Med 2000;50(1):3-10.

26. Weyne GRS. Determinação do tamanho da amostra em pesquisas experimentais na área de saúde. Arq Med ABC 2004;29(2):87-90.

27. Lohman TG, Roche AF, Martorell R. Anthropometric Standardization Reference Manual. Champaign: Human Kinetics; 1988.

28. Craig CL, Marshall AL, Sjöström M, et al. International physical activity questionnaire: 12-country reliability and validity. Med Sci Sports Exerc 2003;35(8):1381-95.

29. Matsudo S, Araujo T, Matsudo V. Questionário internacional de atividade física (IPAQ): estudo de validade e reprodutibilidade no Brasil. Rev Bras Ativ Fis Saúde 2001;6(2):5-18.

30. Ciconelli RM, Ferraz MB, Santos W, et al. Tradução para a língua portuguesa e validação do questionário genérico de avaliação de qualidade de vida SF-36 (Brasil SF-36). Rev Bras Reumatol 1997;39(3):143-50.

31. Ware JE, Gandek B. The SF-36 Health Survey: Development and use in mental health research and the IQOLA Project. Int J Ment Health 1994;23(2):49-73.

32. Mcardle WD, Katch FI, Katch VL. Fisiologia do exercício: nutrição e desempenho humano. 5. ed. Rio de Janeiro: Guanabara Koogan; 2001.

33. Garber CE, Blissmer B, Deschenes MR, et al. American College of Sports Medicine. Quantity and quality of exercise for developing and maintaining cardiorespiratory, musculoskeletal, and neuromotor fitness in apparently healthy adults: guidance for prescribing exercise. Med Sci Sports Exerc 2011;43(7):1334-59. Doi: 10.1249/MSS.0b013e318213fefb.

34. Tanaka H, Monahan KD, Seals DR. Age-predicted maximal heart rate revisited. J Am Coll Cardiol 2001;37(1):153-6.

35. Borg GA. Psychophysical bases of perceived exertion. Med Sci Sports Exerc 1982;14(5):377-81.

36. Bland JM, Altman DGA. Analysis of continuous data from small samples. BMJ 2009;338:a3166. Doi: 10.1136/bmj. a3166.

37. Assembléia Legislativa de Santa Catarina (ALESC). Comissão de Legislação Participativa debate a segurança na Grande Florianópolis. Associação de Militares Oficiais de Santa Catarina 2014. [acesso em 09 mar. 2014]. Disponível em: http://www.acors.org.br/pagina/1163/comissaodelegislacaoparticipativadebateasegurancanagrandeflorianopolis.

38. Birzer ML, Craig DE. Gender Differences in Police Physical Ability Test Performance. Am. J. Police 1996;15(2):93108. Doi: $10.1108 / 07358549610122494$.

39. Boyce B, Jones GR, Lloyd CL, et al. A longitudinal observation of police: body composition changes over 12 years with gender and race comparisons. J Exerc Physiol Online 2008;11:1-12.

40. Ramey SL, Downing NR, Franke WD. Milwaukee police department retirees: cardiovascular disease risk and morbidity among aging Law enforcement officers. AAOHN J 2009;57(11):448-53. Doi: 10.3928/08910162-20091019-02.

41. Silva FC, Hernandez SS, Arancibia BA, et al. Health-related quality of life and related factors of military police officers. Health Qual Life Outcomes 2014;12(1):1-8. Doi: 10.1186/1477-7525-12-60.

42. Santana AM, Gomes JK, De March D, et al. Occupational stress, working condition and nutritional status of military police officers. Work 2012;41(Suppl 1):2908-14. Doi: 10.3233/WOR-2012-0543-2908.

43. Koning L, Merchant AT, Poque J, et al. Waist circumference and waist-to-hip ratio as predictors of cardiovascular events: meta-regression analysis of prospective studies. Eur Heart J 2007;28(7):850-856.

44. Minayo MCS, Assis SG, Oliveira RVC. Impacto das atividades profissionais na saúde física e mental dos policiais civis e militares do Rio de Janeiro (RJ, Brasil). Ciênc Saúde Coletiva 2011;16(4):2199-2209. Doi: 10.1590/S141381232011000400019.

45. Prado ES, Dantas EHM. Efeitos dos exercícios físicos aeróbio e de força nas lipoproteínas HDL, LDL e lipoproteína (a). Arq Bras Cardiol 2002;79(4):429/433. Doi: 10.1590/S0066-782X2001300013.

46. Kallio V, Hämäläinen H, Hakkila J, et al. Reduction in sudden death by a multifactorial intervention program after acute myocardial infarction. Lancet 1979;2:1091-1094.

47. Oberman A, Cleary P, Larosa JC, et al. Changes in risk factors among participants in a long-term exercise rehabilitation program. Adv Cardiol 1982;31:168-175. 
48. Wilhllmsln L, Sanne H, Elmfeldt D et al. A controlled trial of physical training after myocardial infarction. Prev Med 1975;4(4):491-508.

49. Savage PD, Brochu M, Poehlman ET, et al. Reduction in obesity and coronary risk factors after high caloric exercise training in overweight coronary patients. Am Heart J 2003;146(2):317-23.

CORRESPONDING AUTHOR Franciele Cascaes da Silva Adapted Physical Activity Laboratory University of State of Santa Catarina Pascoal Simone Street, 358, Coqueiros

Zip Code: $88080-350$ Florianópolis - SC/ Brazil +554833218651 francascaes@yahoo.com.br
Submitted: 07/07/2015 $1^{\text {st. }}$ Review: $10 / 05 / 2015$ $2^{\text {nd. }}$. Review: 11/12/2015 Accepted: 11/30/2015 
